\title{
Effects of iodinated contrast agent on HU-based dose calculation and dose delivered in iridium-192 high-dose-rate brachytherapy
}

\author{
Dr. Christian Scherf, PhD ${ }^{*}$, PD Dr. Ulla Ramm, PhD ${ }^{*}$, Thomas Stein, MSc², Martin Trommel, MSc', PD Dr. Nikolaos Tselis, MD!, \\ Dr. Georgios Chatzikonstantinou, MD', Dr. Markus Diefenhardt, MD', Prof. Dr. Claus Rödel, MD', Dr. Janett Köhn, PhD', \\ Dr. Jörg Licher, PhDl \\ ${ }^{*}$ Christian Scherf and Ulla Ramm contributed equally to this work. \\ 'Department of Radiation Oncology, University Hospital, Goethe University. Frankfurt, Germany, 2University of Applied Sciences Ansbach, \\ Ansbach, Germany
}

\begin{abstract}
Purpose: This study compares the effect of iodinated contrast agent on Hounsfield unit (HU)-based TG-186 dose calculation vs. delivered dose for high-dose-rate (HDR) iridium-192 brachytherapy using a phantom model.

Material and methods: A reservoir filled with a diluted contrast agent was placed inside a water phantom. A single steel needle applicator was centrally positioned inside the reservoir. Computed tomography (CT) datasets of five different contrast agent dilutions ( 25 to $300 \mathrm{mg} / \mathrm{ml}$ iodine concentration) were acquired, and dose calculations were performed with TG-186 ACE dose calculation formalism of Oncentra ${ }^{\circledR}$ Brachy (Elekta). The dose was measured with a PinPoint ${ }^{\circledR}$ ionization chamber (PTW) inside the contrast agent. ACE calculated and measured data were compared.

Results: For the different contrast agent dilutions, averaged Hounsfield units from $453 \pm 21$ to $2623 \pm 221$ were obtained. Electron densities derived from CT data were significantly higher than corresponding electron densities calculated from chemical compositions. Consequently, the measured dose was higher than corresponding HU-based calculated dose. Relative deviation ranged from $2.5 \%$ to $7 \%$ per $10 \mathrm{~mm}$ penetration depth, depending on contrast agent concentration.

Conclusions: The application of HU-based TG-186 dose formalisms in the presence of high-Z contrast agent bulks overestimates electron densities. Consequently, HU-based dose calculations result in a higher delivered dose than expected from the treatment planning system.

Key words: dose calculation, contrast agent, TG-186, Hounsfield unit, electron density.

\section{Purpose}

Interstitial and intracavitary brachytherapy treatment is most commonly planned, based on computed tomography (CT) scans of patients with implanted catheters or applicators. Most clinical treatment plans are still calculated according to the classical TG-43 formalism, using a line source and anisotropic dose function in pure water $[1,2]$. However, dose information regarding Hounsfield unit (HU)-related electron density information from CT scans arouse growing interest in clinical routine.

Recent algorithms of commercial treatment planning systems (TPS), such as Oncentra ${ }^{\circledR}$ Brachy (Elekta AB, Sweden) or BrachyVision ${ }^{\mathrm{TM}}$ (Varian Medical Systems Inc., USA) [3-8] allow for more sophisticated calculations considering variable electron densities with individual radi- ation scattering and absorption functions. These so-called 'model-based dose calculation algorithms' (MBDCA) are designed for clinical use following the guidelines of TG-186 report [3]. MBDCA either use CT numbers (i.e., Hounsfield unit-based electron densities) or manually assigned electron densities for specific tissues or materials in irradiated regions of interest (ROI). Oncentra ${ }^{\circledR}$ Brachy TPS supports manual density allocation, with a limited number of pre-defined material types as well as CTbased electron density and mass density conversion, with a HU-related lookup table according to a method of Knöös, Nilsson, and Ahlgren [9] (which is only limited to a HU maximum of 3365 in the software). This electron density conversion formalism is intended for human tissue due to a limitation that it assumes only a minor content of high atomic number materials (high-Z). It is not

\footnotetext{
Address for correspondence: Christian Scherf, Department of Radiation Oncology, University Hospital, Received: 08.11 .2021 Goethe University, Frankfurt, Theodor-Stern-Kai 7, 60590 Frankfurt, Germany, phone: +49-69-6301-84344, Accepted: 03.01.2022 fax: +49-69-6301-5538, e-mail: Christian.Scherf@kgu.de Published: 18.02 .2022
} 
designed for application with metal implants and other high-Z materials with $\mathrm{HU} \geq 1000$ [9], as most X-ray concentrated contrast agents.

However, iodinated contrast agents may be requested for treatment planning CT scans to enhance visibility of tumors and organs at risk. The presence of contrast agents will affect HU numbers and consequently HU-based TG-186 dose calculations.

Previous investigations have already shown the measurable dosimetric effects of radiographic contrast agents in balloon applicators and catheter heterogeneities [8, 11-16]. A $2 \mathrm{~cm}$ phantom layer filled with $367 \mathrm{mg} / \mathrm{cm}^{3}$ iodine concentration instead of water between iridium-192 $\left({ }^{192} \mathrm{Ir}\right)$ high-dose-rate (HDR) source and parallel plate ion chamber, resulted in a relative dose reduction down to $90 \%$ and $91 \%$ in the measured dose and Monte Carlo calculations, respectively [13]. Model-based calculation instead of TG-43 formalism close to steel catheters inside a breast implant target volume significantly reduced the calculated volume, receiving $150 \%$ and $200 \%\left(\mathrm{~V}_{150 \%}\right.$ and $\mathrm{V}_{200 \%}$ ) [8]. Contrast agents may also be applied for intended dose sparing of organs at risk, up to $15 \%$ (bladder and rectum walls in vaginal balloon packing) [16]

In this study, we investigated the effect of contrast agent in the surrounding of the brachytherapy source. A phantom model was applied to evaluate the impact on the dose to specific ROI for interstitial implants, and HU-based dose calculation with significant concentrations of contrast agent was used for CT imaging. The effect of diluted contrast agent on electron densities and dose calculations for ${ }^{192} \mathrm{Ir}$ brachytherapy source was compared with the measured dose in the presence of contrast agent. The effects were demonstrated in a water phantom model with an interior reservoir filled with diluted contrast agent.

\section{Material and methods \\ Phantom and study design}

A phantom with a water-filled polyethylene box was used to examinate dose calculations and dose mea- surements based on CT scans (Figure 1). To simulate the presence of iodinated contrast agent inside a specific ROI, a reservoir was centrally placed in the phantom and filled with $700 \mathrm{~cm}^{3}$ diluted iodinated contrast agent. The commercial contrast agent Imeron ${ }^{\circledR} 350$ (Bracco Imaging S.p.A, Italy) mainly consists of iomeprol with $350 \mathrm{mg}$ iodine concentration per ml. Imeron ${ }^{\circledR} 350$ was diluted with distilled water to obtain concentrations of $25,50,100,200$, and $300 \mathrm{mg}$ iodine per $\mathrm{ml}$. Pure water ( $0 \mathrm{mg} / \mathrm{ml}$ iodine concentration) was used as a reference. A $1.9 \mathrm{~mm}$ interstitial brachytherapy steel needle was centrally positioned in the reservoir, and a small PinPoint ${ }^{\circledR}$ ionization chamber (PTW, Freiburg, Germany) was used to measure relative dose.

\section{Computed tomography}

Computed tomography images of the phantom were acquired with a Philips Brilliance Big Bore Oncology CT scanner at $120 \mathrm{kV}$, with a typical pelvis brachytherapy protocol using $204 \mathrm{~mA}$ tube current $(250 \mathrm{mAs})$. Image reconstruction from helical data was done for $1.5 \mathrm{~mm}$ slice thickness for further use with Oncentra ${ }^{\circledR}$ Brachy TPS. Scans were performed with pure water and the diluted contrast agent up to $300 \mathrm{mg} / \mathrm{ml}$ iodine.

The CT numbers for the diluted contrast agent were obtained by evaluating rectangular ROIs of 1980 CT voxels $\left(925 \mathrm{~mm}^{2}\right)$ within the centrally located reconstructed slice of the phantom (Figure 2). Electron densities $\rho_{\mathrm{e}(\mathrm{CT})}$ were derived from the CT data according to a method of Knöss et al. [9].

$$
\rho_{\mathrm{e}(\mathrm{CT})}=\left(\mathrm{A}+\mathrm{B} \times \mathrm{HU} \times 10^{-3}\right) \times 10^{23} \mathrm{~cm}^{-3}
$$

with $A=3.30$ and $B=3.40$ for $-1000<\mathrm{HU}<150$, and $\mathrm{A}=3.65$ and $\mathrm{B}=1.22$ for $150<\mathrm{HU}<1000$. The relationship between HU and $\rho_{\mathrm{e}}$ used in the treatment planning system was based on this equation [10].

To compare the diluted contrast agent (contains iodine as high- $Z$ chemical element) with human tissue (only low- and medium-Z chemical elements), four selected tissue equivalent materials from a Gammex 467 tis-
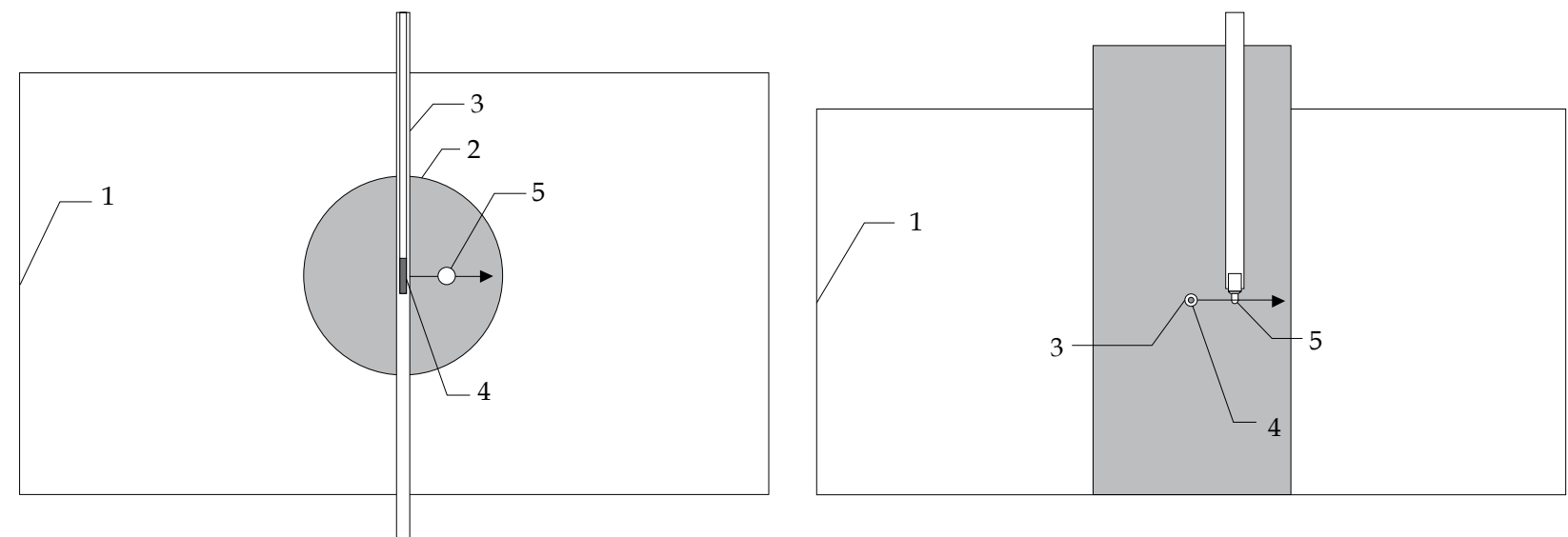

Fig. 1. Schematic drawing of experimental setup (top and front views). Water filled $30 \times 17 \times 15 \mathrm{~cm}^{3}$ phantom geometry (1) with interior reservoir of $8 \mathrm{~cm}$ diameter (2), $200 \mathrm{~mm}$ long interstitial brachytherapy steel needle with $1.9 \mathrm{~mm}$ diameter (3), ${ }^{192} \mathrm{Ir}$ source (4), and PinPoint ${ }^{\circledR}$ chamber PTW 31016 with $4.3 \mathrm{~mm}$ outer diameter (5) for dose measurements. The arrow indicates the scanning direction of the chamber 

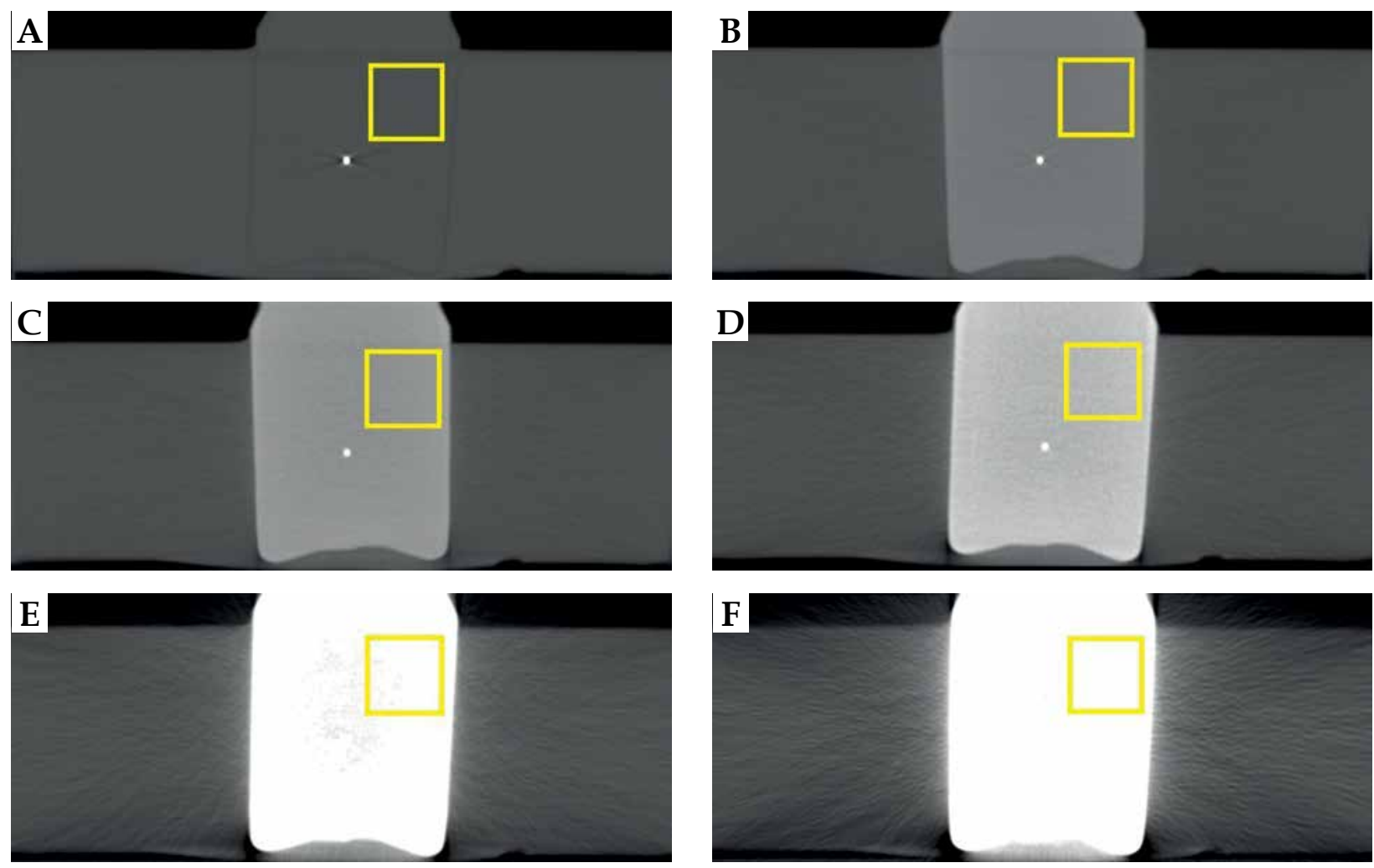

Fig. 2. Central CT slices (axial view) for water (A) and different contrast agent concentrations inside the reservoir (B-F: 25, 50, 100, 200, and $300 \mathrm{mg} / \mathrm{ml}$ iodine concentration). Pixel values inside the highlighted squares were used to determine the averaged $\mathrm{HU}$ values

sue characterization phantom (Sun Nuclear Corp., USA) were also scanned at $120 \mathrm{kV}$ tube voltage: LV1-liver, CB2-resin with $30 \% \mathrm{CaCO}_{3}$, CB2-resin with $50 \% \mathrm{CaCO}_{3}$ and SB3 cortical bone.

\section{Calculation of electron densities from chemical structure}

In addition, a second approach was used to derive electron densities $\rho_{\mathrm{e}(\mathrm{calc})}$ from chemical composition of a compound. For each concentration of diluted contrast agent, the parts of iomeprol and water were calculated, including mass densities and relative fractions of chemical elements, as it was explained by Seco and Evans [17]:

$$
\rho_{\mathrm{e}(\text { calc })}=\frac{\rho_{\mathrm{m}}}{\mathrm{u}} \times \sum_{\mathrm{i}} \mathrm{f}_{\mathrm{i}} \times\left(\frac{\mathrm{Z}}{\mathrm{A}}\right)_{\mathrm{i}}
$$

with the mass density of the compound $\rho_{m}$, the atomic mass unit $\mathrm{u}$, the atomic number to atomic weight ratios of the chemical elements $\sum_{\mathrm{i}_{\mathrm{i}}} \times\left(\frac{\mathrm{Z}}{\mathrm{A}}\right)_{\mathrm{i}}=<\mathrm{Z} / \mathrm{A}>$ summed
over their mass fractions $\mathrm{f}_{\mathrm{i}}$.

According to the manufacturer specification, Imeron ${ }^{\circledR}$ 350 with $350 \mathrm{mg} / \mathrm{ml}$ iodine concentration contains $71.44 \mathrm{~g}$ iomeprol per $100 \mathrm{~cm}^{3}$. For further calculations, it was assumed that the contrast agent dilutions only consist of iomeprol $\left(\mathrm{C}_{17} \mathrm{H}_{22} \mathrm{I}_{3} \mathrm{~N}_{3} \mathrm{O}_{8}\right.$, molar weight $777.087 \mathrm{u}$, mass density $\left.2.27 \mathrm{~g} / \mathrm{cm}^{3}[18]\right)$ and water $\left(\mathrm{H}_{2} \mathrm{O}\right.$, molar weight $18.015 \mathrm{u}$ ). Low concentrated other ingredients of Imeron ${ }^{\circledR}$, like trometamol and hydrochloric acid, were neglected in calculations. Contrast agent and water were mixed in dif- ferent ratios, as presented in Table 1, with their resulting mass densities $\rho_{m}$ and weighted sums of $\langle\mathrm{Z} / \mathrm{A}\rangle$.

Electron densities $\rho_{\mathrm{e}(\mathrm{calc})}$ of Gammex 467 tissue-like compounds were calculated based on their chemical compositions, published by Landry et al. [19].

\section{Dose measurements and CT-based collapsed cone dose calculations}

Dose calculations and dose measurements were performed in the same setup for one ${ }^{192}$ Ir single-source position in the center of the reservoir. Radial dose distribution was calculated for each dilution using corresponding CT data set. A set of dose points from $1.0 \mathrm{~mm}$ up to $30.0 \mathrm{~mm}$ distances perpendicular to the center of the source axis was defined for the calculations. For measurements, the set of dose points started from $3.1 \mathrm{~mm}$ due to geometrical limitation. Smaller distances were not possible, as the needle and the ion chamber were in touch at a distance of $3.1 \mathrm{~mm}$ between their central axes.

Dose measurements were carried out in the above-described phantom placed inside a tank of MP3 motorized water phantom system (PTW, Freiburg, Germany), similarly described by Rossi et al. [20]. Iridium-192 source of Elekta Flexitron ${ }^{\circledR}$ afterloader was positioned in the geometric center of the contrast agent reservoir according to Figure 1 for each measured set of points. A small PTW 31016 PinPoint ${ }^{\circledR}$ chamber was automatically moved by the motorized system perpendicular to Flexisource axis in $0.5 \mathrm{~mm}$ steps within the contrast agent reservoir. Dose-rate was integrated 
Table 1. Volume ratios used to prepare different iodine concentrations, followed by their calculated mass densities (at $20^{\circ} \mathrm{C}$ ) and mean Z/A values. Pure water and pure Imeron ${ }^{\circledR} 350$ are also listed. Only iomeprol and water were considered in these calculations, and molecular interaction effects to the volume of the liquid mixture were neglected

\begin{tabular}{lcccccc}
$\begin{array}{l}\text { Iodine } \\
\text { concentration }\end{array}$ & $\begin{array}{c}\text { Volume fraction } \\
\text { Imeron }{ }^{\circledR} 350 \\
{[\%]}\end{array}$ & $\begin{array}{c}\text { Volume fraction } \\
\text { water [\%] }\end{array}$ & $\begin{array}{c}\text { Weight fraction } \\
\text { iomeprol } \\
{\left[\mathrm{g} / \mathrm{cm}^{3}\right]}\end{array}$ & $\begin{array}{c}\text { Weight fraction } \\
\text { water } \\
{\left[\mathrm{g} / \mathrm{cm}^{3}\right]}\end{array}$ & $\begin{array}{c}\text { Mass density } \\
\rho_{\mathrm{m}} \\
{\left[\mathrm{g} / \mathrm{cm}^{3}\right]}\end{array}$ & $\langle\mathrm{Z} / \mathrm{A}\rangle$ \\
\hline $\begin{array}{l}\mathrm{O} \mathrm{mg} / \mathrm{ml} \\
\text { (pure water) }\end{array}$ & 0.0 & 100.0 & 0.0 & 0.998 & 0.998 & 0.5551 \\
\hline $25 \mathrm{mg} / \mathrm{ml}$ & 7.1 & 92.9 & 0.051 & 0.976 & 1.027 & 0.5510 \\
\hline $50 \mathrm{mg} / \mathrm{ml}$ & 14.3 & 85.7 & 0.102 & 0.953 & 1.055 & 0.5472 \\
\hline $100 \mathrm{mg} / \mathrm{ml}$ & 28.6 & 71.4 & 0.204 & 0.908 & 1.112 & 0.5401 \\
\hline $200 \mathrm{mg} / \mathrm{ml}$ & 57.1 & 42.9 & 0.408 & 0.819 & 1.227 & 0.5280 \\
\hline $300 \mathrm{mg} / \mathrm{ml}$ & 85.7 & 14.3 & 0.612 & 0.729 & 1.341 & 0.5178 \\
\hline $\begin{array}{l}350 \mathrm{mg} / \mathrm{ml} \\
\left(\mathrm{pure} \mathrm{meron}{ }^{\circledR} \text { 350) }\right.\end{array}$ & 100.0 & 0.0 & 0.714 & 0.684 & 1.398 & 0.5134
\end{tabular}

for 5 seconds per step using a TANDEM electrometer and MEPHYSTO mc $^{2}$ software (PTW, Freiburg, Germany).

These axial dose point measurements were acquired for water and all contrast agent dilutions. The effect of source position fluctuations was minimized according to Schoenfeld et al. [21] by searching a maximum dose-rate position in $\mathrm{Y}$ and $\mathrm{Z}$ directions for every source cycle, with $0.1 \mathrm{~mm}$ step resolution.

The measured data of different contrast agent concentrations were always evaluated relative to the measured pure water data as reference. This enabled us to assess the data independently of calibration effects and correction factors. PinPoint ${ }^{\circledR}$ chamber, with a volume of $0.015 \mathrm{~cm}^{3}$ has an almost constant relative response (variation $<1 \%$ ) with respect to expected radial variation of the mean photon energy [22].

A

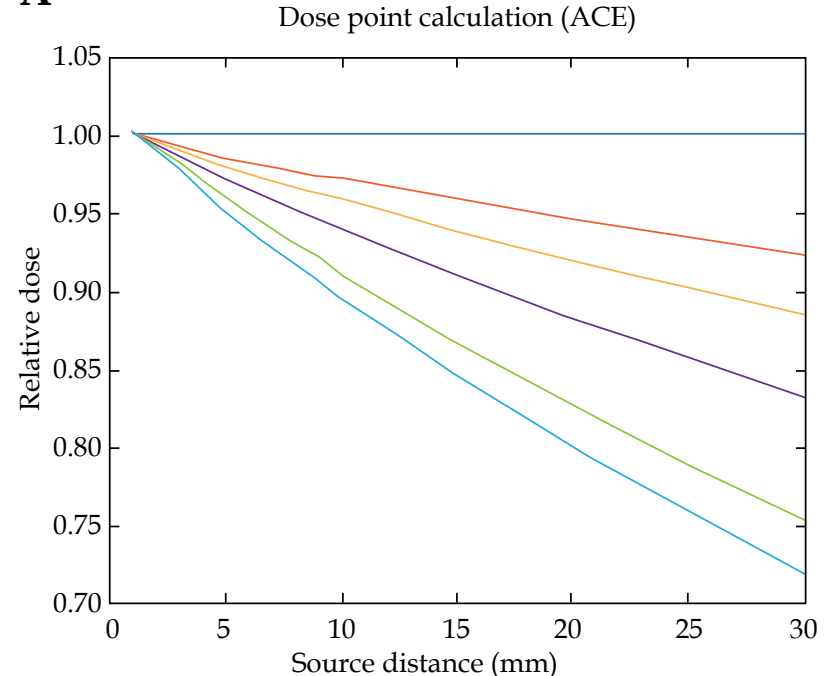

Therefore, an impact to the measured dose related to additional beam hardening due to the presence of iodine, can be neglected. Thus, all known correction factors for volume averaging, position of the chamber's effective point of measurement, and radiation quality [21] resulted in the value of 1 .

Finally, the relative consideration of measured and calculated data eliminated the dominating geometrical $1 / r^{2}$ dependency and small attenuation factor of the steel needle $(\sim 1.7 \%)$ in all evaluations and from the graphs in Figures 3 and 4 .

Dose calculations were performed with ACE collapsed cone algorithm of Oncentra ${ }^{\circledR}$ Brachy [4]. TPS was commissioned based on the published consensus data of Flexisource [23]. Mass density was HU dependently assigned to each voxel of 3D-CT data, with a lookup table

B

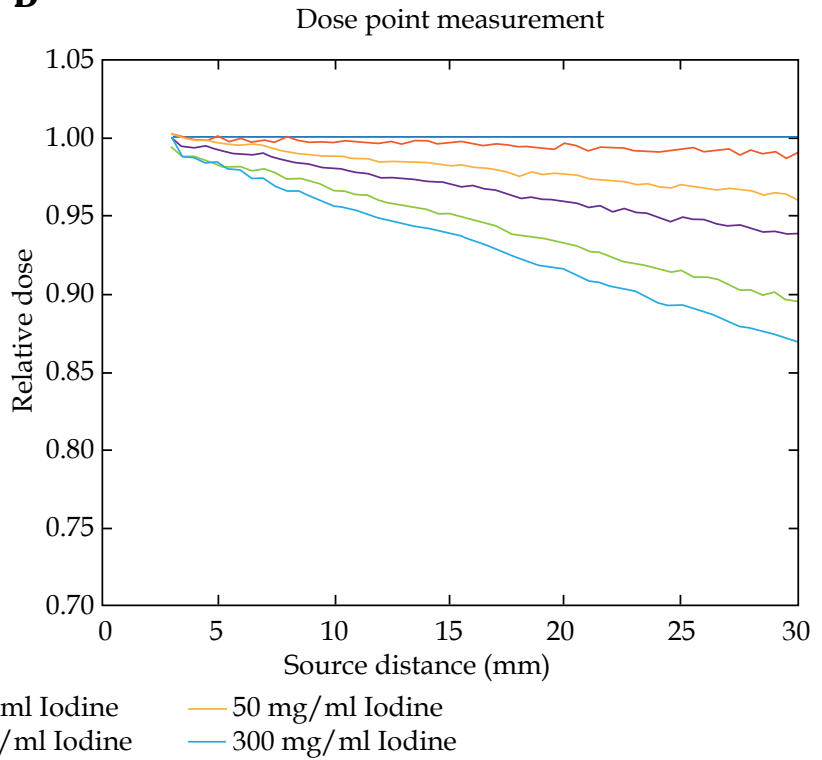

Fig. 3. A) Results of dose point calculations in the TPS for pure water and diluted contrast agent in the reservoir. All collapsed cone ACE data was calculated HU-based with corresponding CT data starting at the applicator surface. B) Results of dose point measurements with PinPoint ${ }^{\circledR}$ ionization chamber, starting at the closest possible distance. All data are relatively normalized to the dose measured in pure water 


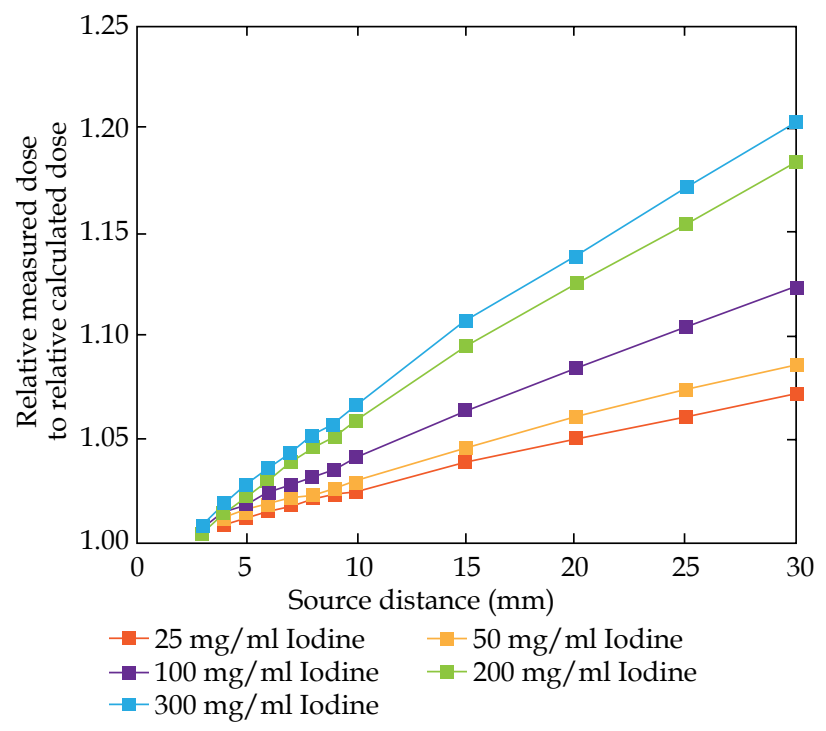

Fig. 4. Ratio of measured normalized dose points to normalized calculated dose points depending on the source to detector/dose point distance

that applies the method of Knöös et al. [9] as described in the CT section. Dose was calculated with high accuracy level of the software, applying $1 \times 1 \times 1 \mathrm{~mm}^{3}$ voxels in a $10 \mathrm{~cm}$ bounding box, and $2 \times 2 \times 2 \mathrm{~mm}^{3}$ voxels in a $20 \mathrm{~cm}$ bounding box, based on isocenter of the active dwell position $[4,5]$.

\section{Results}

\section{Electron densities derived from CT and calculated from chemical structure}

The electron densities derived from both approaches, i.e. obtained from CT and calculated from chemical compositions, are shown in Table 2 and illustrated in Figure 5.

The measured mean $\mathrm{HU}_{\mathrm{CT}}$ numbers obtained from CT scans and their derived electron densities of the contrast agent dilutions and of the selected tissue equivalent materials, are also listed in Table 2. Reduced X-ray transmission related to higher iodine concentrations resulted in increasing standard deviation and saturation effects of the determined HU values. According to Equation 1, for both, diluted contrast agent and phantom materials, electron densities and electron densities relative to water were calculated. The mass densities and the calculated electron densities that were obtained from the chemical compositions were calculated by applying Equation 2 .

Both approaches yielded different values for electron densities. The comparison of contrast agent dilutions showed significant higher values for the HU-based electron densities. With increasing iodine concentration, the relative deviation ranged from $+24 \%$ for $25 \mathrm{mg} / \mathrm{ml}$, up to $+65 \%$ for $300 \mathrm{mg} / \mathrm{ml}$. The CT derived relative electron densities obtained from Gammex phantom materials showed only moderate deviations from the calculated values. Their relative deviations ranged from $-5.5 \%$ for the SB3 cortical bone, up to $+3.1 \%$ for the LV1-liver equivalent phantom material.

\section{Dose point evaluation}

Figure 3A demonstrates dependency of the calculated dose as a function of the radial source distance and of the iodine concentration. Each set of dose points for the diluted contrast agent was calculated relative to the corresponding set of dose points in water. In consequence, the radial $1 / r^{2}$ decay was cancelled out in the diagram.

Figure $3 \mathrm{~B}$ shows dependency of the measured dose as a function of the radial source distance and the iodine concentration. Each set of dose points for the diluted con-

Table 2. Measured $\mathrm{HU}$ numbers $\left(\mathrm{HU}_{\mathrm{CT}}\right)$ and derived electron densities $\left(\rho_{\mathrm{e}, \mathrm{CT}}\right)$, absolute and relative to water of the contrast agent dilutions and selected Gammex phantom materials. Standard deviations result from statistical evaluation of CT data. Mass densities $\left(\rho_{\mathrm{m}}\right)$ and calculated electron densities $\left(\rho_{\mathrm{e}, \mathrm{calc}}\right)$ of each atomic composition, absolute, and relative to water

\begin{tabular}{|c|c|c|c|c|c|c|}
\hline $\begin{array}{l}\text { lodine concentration } \\
\text { and phantom material }\end{array}$ & $\begin{array}{c}\mathrm{HU}_{\mathrm{CT}} \\
(120 \mathrm{kV})\end{array}$ & $\begin{array}{c}\rho_{\mathrm{e}, \mathrm{CT}} \\
{\left[10^{23} \mathrm{~cm}^{-3}\right]}\end{array}$ & $\begin{array}{c}\rho_{\mathrm{e}, \mathrm{CT}} \\
\text { relative to } \\
\text { water }\end{array}$ & $\begin{array}{c}\rho_{m} \\
{\left[\mathrm{~g} / \mathrm{cm}^{3}\right]}\end{array}$ & $\begin{array}{c}\rho_{\mathrm{e}, \text { calc }} \\
{\left[10^{23} \mathrm{~cm}^{-3}\right]}\end{array}$ & $\begin{array}{c}\rho_{\mathrm{e}, \mathrm{calc}} \\
\text { relative to } \\
\text { water }\end{array}$ \\
\hline \multicolumn{7}{|l|}{ Contrast agent } \\
\hline $0 \mathrm{mg} / \mathrm{ml}$ (pure water) & $2 \pm 8$ & $3.31 \pm 0.03$ & $1.00 \pm 0.01$ & 0.998 & 3.340 & 1.000 \\
\hline $25 \mathrm{mg} / \mathrm{ml}$ & $453 \pm 21$ & $4.20 \pm 0.03$ & $1.27 \pm 0.01$ & 1.027 & 3.415 & 1.021 \\
\hline $50 \mathrm{mg} / \mathrm{ml}$ & $793 \pm 38$ & $4.62 \pm 0.05$ & $1.40 \pm 0.01$ & 1.055 & 3.483 & 1.042 \\
\hline $100 \mathrm{mg} / \mathrm{ml}$ & $1283 \pm 60$ & $5.22 \pm 0.07$ & $1.58 \pm 0.02$ & 1.112 & 3.620 & 1.085 \\
\hline $200 \mathrm{mg} / \mathrm{ml}$ & $2129 \pm 142$ & $6.25 \pm 0.17$ & $1.89 \pm 0.03$ & 1.227 & 3.901 & 1.169 \\
\hline $300 \mathrm{mg} / \mathrm{ml}$ & $2623 \pm 221$ & $6.85 \pm 0.27$ & $2.07 \pm 0.04$ & 1.341 & 4.179 & 1.254 \\
\hline \multicolumn{7}{|l|}{ Gammex } \\
\hline LV1-liver & $93 \pm 17$ & $3.62 \pm 0.06$ & $1.10 \pm 0.02$ & 1.096 & 3.560 & 1.067 \\
\hline $\mathrm{CB} 2-30 \% \mathrm{CaCO}_{3}$ & $513 \pm 22$ & $4.28 \pm 0.03$ & $1.30 \pm 0.01$ & 1.331 & 4.268 & 1.279 \\
\hline $\mathrm{CB} 2-50 \% \mathrm{CaCO}_{3}$ & $915 \pm 25$ & $4.77 \pm 0.03$ & $1.44 \pm 0.01$ & 1.559 & 4.911 & 1.472 \\
\hline SB3 cortical bone & $1376 \pm 29$ & $5.33 \pm 0.04$ & $1.61 \pm 0.01$ & 1.822 & 5.666 & 1.698 \\
\hline
\end{tabular}


trast agent was normalized to the corresponding set of dose points in water.

For further comparison of data displayed in Figure 3, the derived ratio of measured normalized dose points to normalized calculated dose points is shown in Figure 4.

The discrepancy between dose calculation and dose measurement increased with the iodine concentration as well as with the size of contrast bulk. Penetrating small contrast agent bulks resulted in small dose errors, i.e. approximately $1 \%$ to $3 \%$ for $5 \mathrm{~mm}$ depth of penetration. The errors increased up to $7 \%$ for lower concentrations and up to $20 \%$ for higher concentrations of the contrast agent for the largest measured penetration depth of $30 \mathrm{~mm}$.

\section{Discussion}

In clinical treatment planning, contrast agents are widely used to enhance visualization of soft tissue. This study showed that the presence of iodinated contrast agent affected model-based dose calculations if electron densities derived from HU numbers were used for treatment planning. The electron densities of all contrast agent dilutions obtained from CT data were significantly higher than the calculated values from the chemical composition. These deviations were related to CT X-ray spectrum that was dominated by lower energy photons. They mainly interact with matter through photo-electric effect, in particular with high- $Z$ elements, due to prominent $Z^{4}$ dependence. Due to the resulting high $X$-ray attenuation for iodine and other high- $Z$ materials, the electron densities derived from CT data are overestimated. This also results in an overestimation of attenuation for ${ }^{192} \mathrm{Ir}$ radiation quality. These facts are in accordance with the general Monte Carlo simulations of radiation energy-dependence of mass attenuation coefficients $(\mu / \rho)$, and the effective electron densities for different iodinated contrast agents published by Al-Buriahi and Tonguc [24].

Because of the overestimated densities derived from $\mathrm{HU}$, dose calculation algorithm falsely assumes a too strong photon interaction with the matter. This results in a stronger calculated photon attenuation and mass energy absorption and consequently, manifests itself in a too steep depth dose gradient. The relative deviation between measurement and calculation increases with increasing iodine concentration and deeper penetration into the contrast bulk. Measured dose was always higher than the corresponding HU-based calculation.

From the clinical perspective, this leads in the case of substantially concentrated contrast agent in a risk structure, to an actual higher dose exposure than indicated in treatment plan, which can increase the risk of undesirable side effects. In the case of concentrated contrast agent in clinical target volume, the dose underestimation manifests itself in extended calculated dwell times, i.e., the treated dose will exceed the intended dose of all target volumes and risk structures.

When contrast agent is used to visualize tumor-related information, such as soft tissue and lymph nodes, the typical iodine concentration in CTV does not exceed $25 \mathrm{mg} / \mathrm{ml}$ (i.e., $450 \mathrm{HU}$ ) when planning CT data is acquired. In such cases, the deviation of ACE calculated

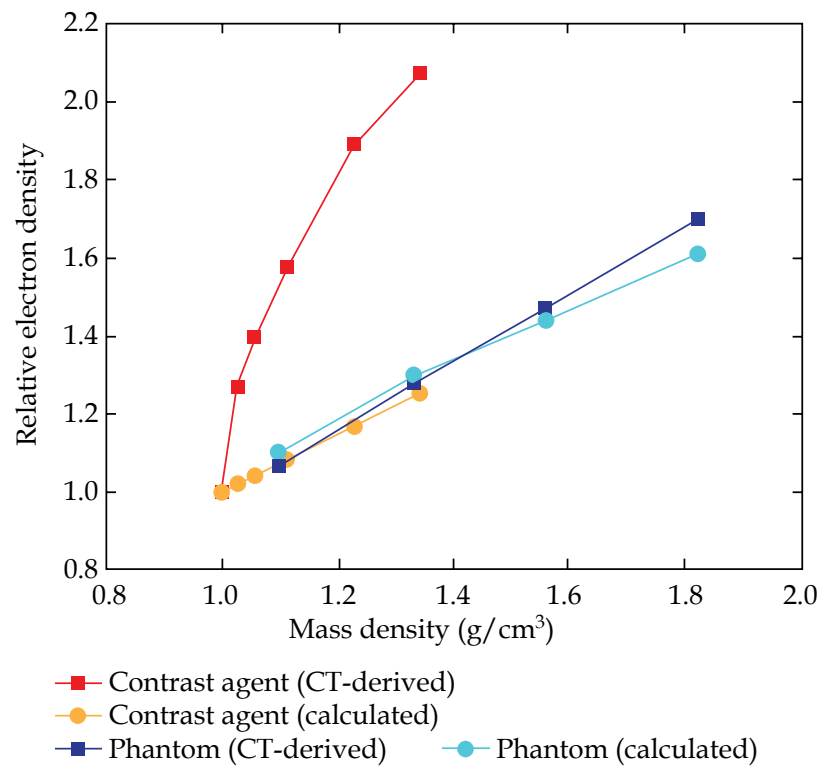

Fig. 5. Relative electron density versus mass density dependence obtained from $\mathrm{CT}$ data and calculated from the chemical composition of water and contrast agent dilutions from $25 \mathrm{mg} / \mathrm{ml}$ to $300 \mathrm{mg} / \mathrm{ml}$ iodine concentrations. Corresponding data of tissue equivalent phantom materials are also included

and delivered dose will differ in less than $2 \%$ at $\leq 10 \mathrm{~mm}$ source distance, and might be of minor importance for a clinical outcome.

The error in dose calculation should be considered relevant from $450 \mathrm{HU}$. In such rare situations, a manual assignment of associated tissue type (i.e., without considering contrast agent) or even of water is more appropriate. For one thing, the actually measured differences according to Figure $3 \mathrm{~B}$ were always less prominent than the HU-based calculated differences, as shown in Figure 3A. Furthermore, the measured dose and the dose to water in Figure 3B differ significantly less than the corresponding HU-based calculated dose and the measured dose, as presented in Figure 4. On the other hand, the relevant contrast agent influence in most clinical situations becomes even smaller due to physiologically-induced decrease in concentration with advancing time between $\mathrm{CT}$ acquisition and radiation treatment.

\section{Conclusions}

The present work demonstrates that the standard HU to electron density conversion formalism of Oncentra ${ }^{\circledR}$ Brachy ACE algorithm overestimates the electron densities of diluted iodinated contrast agent. In presence of contrast agent, the delivered dose will be higher than the corresponding calculated dose. Under such circumstances, the user should keep in mind that HU-based dose calculations will result in erroneous dose information. A discrepancy of $2 \%$ to $7 \%$ per each $10 \mathrm{~mm}$ penetration depth depending on the contrast agent concentration from $25 \mathrm{mg} / \mathrm{ml}(450 \mathrm{HU})$ to $300 \mathrm{mg} / \mathrm{ml}(2600 \mathrm{HU})$ can be estimated. 


\section{Disclosure}

The authors report no conflict of interest.

\section{References}

1. Nath R, Anderson LL, Luxton G et al. Dosimetry of interstitial brachytherapy sources: recommendations of the AAPM Radiation Therapy Committee Task Group No. 43. American Association of Physicists in Medicine. Med Phys 1995; 22: 209-234.

2. Rivard MJ, Coursey BM, DeWerd LA et al. Update of AAPM task group no. 43 report: a revised AAPM protocol for brachytherapy dose calculations. Med Phys 2004; 31: 633-674.

3. Beaulieu L, Tedgren AC, Carrier JF et al. Report of the Task Group 186 on model-based dose calculation methods in brachytherapy beyond the TG-43 formalism: Current status and recommendations for clinical implementation. Med Phys 2012; 39: 6208-6236.

4. van Veelen B, Ma Y, Beaulieu L. ACE advanced collapsed cone engine. White Paper 2014; Elekta AB, Stockholm, Sweden.

5. Ma Y, Lacroix F, Lavallée MC, Beaulieu L. Validation of the Oncentra Brachy Advanced Collapsed cone Engine for a commercial ${ }^{192}$ Ir source using heterogeneous geometries. Brachytherapy 2015; 14: 939-952.

6. Rivard MJ, Beaulieu L, Mourtada F. Enhancements to commissioning techniques and quality assurance of brachytherapy treatment planning systems that use model-based dose calculation algorithms. Med Phys 2010; 37: 2645-2658.

7. Papagiannis $\mathrm{P}$, Pantelis E, Karaiskos P. Current state of the art brachytherapy treatment planning dosimetry algorithms. Br J Radiol 2014; 87: 20140163.

8. Sinnatamby M, Nagarajan V, Reddy KS et al. Dosimetric comparison of Acuros ${ }^{\mathrm{TM}}$ BV with AAPM TG43 dose calculation formalism in breast interstitial high-dose-rate brachytherapy with the use of metal catheters. J Contemp Brachytherapy 2015; 7: 273-279.

9. Knöös T, Nilsson M, Ahlgren L. A method for conversion of Hounsfield number to electron density and prediction of macroscopic pair production cross-sections. Radiother Oncol 1986; 5: 337-345.

10. Oncentra Brachy 4.6, Physics and Algorithms Manual, Elekta AB 2018, Stockholm, Sweden.

11. Williamson JF, Perera H, Li Z, Lutz WR. Comparison of calculated and measured heterogeneity correction factors for 125I, 137Cs, and ${ }^{192}$ Ir brachytherapy sources near localized heterogeneities. Med Phys 1993; 20: 209-222.

12. Kassas B, Mourtada F, Horton JL, Lane RG. Contrast effects on dosimetry of a partial breast irradiation system. Med Phys 2004; 31: 1976-1979.

13. Kirk MC, Hsi WC, Chu JCH et al. Dose perturbation induced by radiographic contrast inside brachytherapy balloon applicators. Med Phys 2004; 31: 1219-1224.

14. Cheng CW, Mitra R, Allen Li X, Das IJ. Dose perturbations due to contrast medium and air in MammoSite ${ }^{\circledR}$ treatment: An experimental and Monte Carlo study. Med Phys 2005; 32: 2279-2287.

15. Oh S, Scott J, Shin DH et al. Measurements of dose discrepancies due to inhomogeneities and radiographic contrast in balloon catheter brachytherapy. Med Phys 2009; 36: 3945-3954.

16. Saini AS, Zhang GG, Finkelstein SE, Biagioli MC. Dose reduction study in vaginal balloon packing filled with contrast for HDR brachytherapy treatment. Int J Radiat Oncol Biol Phys 2011; 80: 1263-1267.

17. Seco J, Evans PM. Assessing the effect of electron density in photon dose calculations. Med Phys 2006; 33: 540-552.

18. https://comptox.epa.gov/dashboard/dsstoxdb/results?utf8 $=\%$ E2 $\% 9$ C $\% 93 \&$ search=Iomeprol (accessed October $25^{\text {th }}$, 2021).
19. Landry G, Seco J, Gaudreault M, Verhaegen F. Deriving effective atomic numbers from DECT based on a parameterization of the ratio of high and low linear attenuation coefficients. Phys Med Biol 2013; 58: 6851-6866.

20. Rossi G, Gainey M, Thomann B et al. Monte Carlo and experimental high dose rate 192-Ir brachytherapy dosimetry with microDiamond detectors. Z Med Phys 2019; 29: 272-281.

21. Schoenfeld AA, Büsing K, Delfs B et al. Reference conditions for ion-chamber based HDR brachytherapy dosimetry and for the calibration of high-resolution solid detectors. Z Med Phys 2018; 28: 293-302.

22. Chofor N, Harder D, Selbach HJ, Poppe B. The mean photon energy $\overline{E F}$ at the point of measurement determines the detector-specific radiation quality correction factor $k \mathrm{Q}, \mathrm{M}$ in ${ }^{192}$ Ir brachytherapy dosimetry. Z Med Phys 2016; 26: 238-250.

23. Perez-Calatayud J, Ballester F, Das RK et al. Dose calculation for photon-emitting brachytherapy sources with average energy higher than $50 \mathrm{keV}$ : full report of the AAPM and ESTRO. Report of the High Energy Brachytherapy Source Dosimetry (HEBD) Working Group (August 2012). American Association of Physicists in Medicine, One Physics Ellipse, College Park, MD 20740-3846.

24. Al-Buriahi MS, Tonguc BT. Mass attenuation coefficients, effective atomic numbers and electron densities of some contrast agents for computed tomography. Radiat Phys Chem 2020; 66: 108507. 